\title{
Multiculturalidad y derechos colectivos en Joseph Raz *
}

\section{Multiculturalism and Collective Rights in Joseph Raz}

\author{
JUAN PABLO ZAMBRANO TIZNADO
}

Universidad Católica de Temuco, Chile

\begin{abstract}
RESUMEN. En este trabajo me propongo mostrar las dificultades de sostener la argumentación de Raz para fundamentar los derechos colectivos en el caso de sociedades multiculturales. Para ello contrasto la argumentación de este autor con la de J. Griffin. Concluyo que si bien existen bienes comunales, en el caso de las sociedades multiculturales la imposibilidad de que estas actúen como unidad de agencia hace muy difícil un acuerdo sobre ellos y, en el caso de existir este acuerdo, el resultado no puede llamarse «derecho» según la teoría del derecho defendida por Joseph Raz.
\end{abstract}

Palabras clave: Derechos Colectivos, Multiculturalidad, Joseph Raz.

\section{Introducción}

Leslie Green, publicó el año 2005 un artículo titulado «Tres temas sobre Raz», la tercera sección de dicho trabajo llevaba por título: «Valor del pluralismo y pluralismo cultural». En esa sección Green muestra el debate entre el propio Raz y el profesor Griffin sobre el fundamento de los derechos colectivos.

Mi objetivo es mostrar algunos aspectos del debate que Green soslaya y que muestran las dificultades de sostener la argumentación de Raz para el caso de sociedades multiculturales.
Abstract. In this paper I intend to show the difficulties of sustaining Raz's argument in support of collective rights in the case of multicultural societies. This is in contrast to the argument of this author with J. Griffin. I conclude that although there are communal property, in the case of multicultural societies the possibility that these act as an agency makes it very difficult to agree on them, and in the event of this agreement, the result can not be called «law» according to the theory of law upheld by Joseph Raz.

Key words: Collective Right, Multiculturalism, Joseph Raz.

Raz, no sólo tolera a grupos sociales viables cuyas formas de vida son incompatibles y que además cohabitan en instituciones políticas comunes (2001, pp. 190 y ss.); su liberalismo multicultural, en palabras de Gargarella (1999, pp. 146 y ss.), le ofrece a estos grupos espacios para florecer. Esto requiere, además, hacer de nuestras diversas instituciones políticas «lugares» hospitalarios para los distintos grupos que conviven en nuestras comunidades (Green, 2005, p. 516).

El Derecho, ubicado dentro del sistema político, permite que emerjan nuevas instituciones tanto legislativas como ju- 
diciales en el contexto de las propias necesidades sociales de la comunidad en que surgen (Raz, 2001, p. 221). Así, las prácticas culturales de grupos minoritarios se muestran como emergencias que requieren el pronunciamiento de la comunidad multicultural.

Entre dichas emergencias se encuentra por ejemplo el deber - y su correlativo derecho- de tolerar ciertas prácticas culturales de grupos minoritarios en la comunidad multicultural.

\section{El Fundamento de los derechos Colectivos: Griffin vs. Raz}

La realidad de que ciertos derechos colectivos se encuentren reconocidos en diversos sistemas jurídicos no elude la cuestión de si la naturaleza de los derechos subjetivos permite la existencia de derechos con este carácter, máxime si algunos de ellos incluso parecen tener el carácter de «derechos humanos colectivos»».

Para Griffin (2003, pp. 160 y ss.; Green, 2005, p. 516), los derechos humanos son apoyos mínimos austeros para la agencia y personería que cumplen la función de limitar la vigencia y aplicación de ciertas prácticas. Esta unidad de agencia es individual, y su carácter institucional - y por tanto colectivo - esta dado por la suma de las individualidades que acuerdan limitar ciertas prácticas, en razón de reconocer ciertos derechos. El carácter individual de la unidad de agencia le hace sostener que no hay razón que justifique la categoría de derechos colectivos y, aunque pueda ser discutible si responden o no, estos derechos a la etiqueta de derechos humanos, Griffin (2003, pp. 160 y ss.), no discute que la unidad de agencia es siempre individual pues no hay razón para pensar que del hecho de que ciertos bienes son compartidos se siga que existan derechos y deberes colectivos. Para Raz (1986, p. 208; Green, 2005, pp. 516 y ss.), algunos bienes colectivos como la tolerancia, en determinados casos pueden justificar deberes y derechos por el bien del grupo en cuanto tal. Para Griffin esto es contraintuitivo.

Un problema secundario es que Griffin entiende que un deber colectivo de tolerancia implica que cada uno de nosotros tendría que realizar acciones tolerantes hacia otros, pero él se olvida que se discute sobre derechos colectivos y entonces no se puede esperar que cada miembro individualmente considerado actue en conformidad con este deber, pues lo esperable es que el Derecho cree condiciones para la realización de la tolerancia, esto es, que cree las condiciones de posibilidad para ella (Raz, 1986, p. 161; Bardazano, 2007, p. 180); en este punto Green tiene razón.

Para Raz (2001, pp. 57 y ss.), alguien tiene derecho sólo si un aspecto de su bienestar es una razón para la existencia del deber. No es necesario que el interés justifique cada deber en particular (Green, 2005, p. 517), pero, replica Griffin (2003, pp. 160 y ss.), esto no muestra que el valor del bien no este individualizado y por tanto este argumento no sirve como fundamento para reconocer la existencia de derechos colectivos.

El problema esta entonces, en a) la forma de entender la existencia de bienes compartidos, y b) la relación entre el individuo y su comunidad.

\section{Los Bienes Compartidos}

Raz (1986, p. 272; Green, 2005, p. 518), expresa que los miembros de la comunidad no ven una relación causal entre el carácter colectivo y el valor individual, sino una relación constitutiva. Lo que le da el valor a la tolerancia como bien colectivo, es el carácter esencialmente compartido del bien; sin embargo no hay derecho sin alteridad y de todo derecho, individual o no, podemos predicar su ca- 
rácter compartido o, en palabras de Griffin su carácter relacional. Sin embargo, no predicamos de todo derecho su carácter colectivo, entonces aún es posible sostener que sea el valor individual la causa del reconocimiento de derechos y deberes colectivos.

Raz (1986, p. 272), además oscurece su argumentación, al afirmar que son los miembros (y no la comunidad) los que ven de una u otra manera la relación entre el valor individual y el carácter colectivo del bien.

El problema es que ambos autores se refieren tanto al carácter colectivo, relacional y compartido de los bienes.

El derecho es siempre relacional en la medida que impone derechos y deberes entre personas. Ello puede implicar o no derechos colectivos. Si damos por hecho la existencia de bienes colectivos lo que hay que aclarar es si la relación entre el bien colectivo y el valor individual es causal o constitutiva.

La titularidad del derecho es siempre individual y lo que justifica en algunos casos la ficción de acciones colectivas o de grupos titulares de derechos es que el disfrute del bien es compartido, pero del hecho de que todos compartamos algo no se sigue que aquello sea de todos. Lo que compartimos en realidad son tres cosas: a) la necesidad personal de realizar nuestros planes de vida b) el hecho que dichos planes de vida se realizan en un espacio y tiempo determinado c) que en dicho espacio común existen otros que también buscan realizar sus planes de vida. Esto nos obliga, por una cuestión fáctica a llegar a acuerdo y a compartir bienes. Pero, siendo constitutivamente así, estos bienes siguen siendo un medio y por tanto están en relación al fin de lograr ciudadanos plenamente desarrollados.

El otro argumento raziano pretende explicar la relación entre el individuo y su comunidad y fundamentar en esa rela- ción la existencia de bienes comunales que justifiquen derechos y deberes.

En síntesis, intenta responder a la pregunta, de si una comunidad multicultural, como Chile, puede actuar como una unidad de agencia respecto por ej. de la decisión de tolerar o no, prácticas culturales que pudieran ser opresivas.

\section{El Enfoque de la Integración}

Lo que ni Green ni Raz expresan, es que respecto de la relación entre individuo y comunidad asumen lo que Dworkin (1992, pp. 205-223) llama el enfoque de la integración.

La forma de entender la relación individuo-comunidad supone que la unidad de agencia apropiada para algunas acciones que afectan al individuo no es éste sino la comunidad a la cuál pertenece, y esto explica que decisiones comunales sobre la libertad, afectan la vida y carácter de esa comunidad y al mismo tiempo afecten a sus miembros por cuanto sus vidas se ven disminuidas al vivir en una comunidad injusta (Dworkin, 1992, p. 223). El problema que sigue en pie, es que Raz supone algo que es difícil de suponer.

La propia idea de unidad de agencia se ve dificultada por la realidad de la multiculturalidad ¿Puede Chile, actuar como unidad de agencia a la hora de decidir que prácticas culturales tolerar? Y me refiero a prácticas tales como aquélla según la cual las mujeres mapuche están sexualmente disponibles a los hombres de la comunidad desde la primera menstruación independientemente de la edad (causa rit 101-2005), o aquélla según la cual un miembro de una familia mapuche a quien han matado ilegítimamente uno de sus integrantes tiene el derecho de matar al agresor (causa rit 049-2006).

La argumentación raziana responde bien a comunidades diversas pero no a comunidades multiculturales. En ellas se discute sobre los derechos que se deben 
reconocer a personas que, aunque actúan como grupo al momento de alegar los derechos sobre los que buscan reconocimiento, no son propiamente una comunidad que exija derechos colectivos en razón de la necesidad que tienen de vivir en una cultura floreciente.

No es lo mismo, la exigencia de derechos de los homosexuales aunque pretendan actuar como colectivo, que la exigencia de derechos del «pueblo mapuche»; en un caso los derechos al fin y al cabo son ejercidos en forma individual, y quienes los ejercen buscan pertenecer como iguales a la comunidad mayoritaria, en el segundo, se busca el reconocimiento en base a categorías colectivas como pueblo y cultura, y por esta razón estos no buscan formar parte de la comunidad mayoritaria sino que ésta cree las condiciones para que su cultura florezca y con ello logren sus miembros un pleno desarrollo.

Una comunidad multicultural es aquella en que existen diversas comunidades culturales estables que tienen voluntad y capacidad para perpetuarse (Raz, 2001, pp. 188 y ss.).

Son esas diversas comunidades las que deben reconocer el carácter colectivo de un bien y establecer los límites en que los derechos y deberes colectivos deben ejercerse. Lo difícil es suponer que estos grupos puedan dejar de actuar como tales y estén dispuestos en la etapa deliberativa por ejemplo, a ceder en la extensión de los derechos que ellos creen tener y que los demás grupos no están dispuestos a reconocer.

Si Griffin no destaca suficientemente el papel de la cultura como espacio de ejercicio de las libertades, en Raz el entusiasmo es excesivo; la existencia de derechos colectivos depende de la posibilidad de que la comunidad multicultural pueda actuar como cuerpo, que todos los grupos culturales, valoren un determinado bien por su carácter colectivo y que además este acuerdo sea expresado en las instancias que la comunidad ha definido.

Esta explicación de los derechos colectivos siendo lógicamente posible requiere una participación y un nivel de acuerdo difícil de alcanzar para una comunidad multicultural. El caso de la tolerancia muestra esta dificultad.

Raz no distingue entre tolerantes sensatos e insensatos. La única razón que justifica la tolerancia es el mayor valor de la autonomía sobre los demás valores en juego; que una sociedad se ponga de acuerdo en permitir ciertas prácticas en razón, de los numerosos que son los grupos que requieren el reconocimiento de un determinado derecho o por la necesidad de estabilidad política, no son casos de tolerancia. Entonces, la sociedad multicultural debe a la hora de ponderar los valores en juego privilegiar la autonomía sobre los demás valores. Esto supone la existencia de una moral positiva común entre los diversos grupos culturales, o en todo caso, la posibilidad de acuerdo sobre ellos, pero cuando el anclaje de estos, se encuentra en cosmovisiones diversas, la posibilidad de acuerdo se vuelve más compleja.

Esto hace que el reconocimiento de derechos colectivos mediante un acuerdo en la etapa de deliberación que se plasme en una determinada consideración positiva autoritativa se vuelva en la práctica dificultoso. La otra opción es que sea el juez quien tenga la posibilidad de reconocer derechos colectivos mediante el ejercicio de la discrecionalidad.

\section{Conclusión}

Los bienes compartidos lo son constitutivamente, pero esto no niega que ellos tengan una finalidad individual. Admitiendo que ciertos bienes requieren para su logro de la colectividad, las personas aceptan realizarlo y ponen su logro en 
común porque consideran a un determinado bien valioso para su propio desarrollo.

En el caso de la relación individuocomunidad la única forma de que existan consideraciones positivas autoritativas que reconozcan derechos colectivos es que los diversos grupos se pongan de acuerdo en la etapa deliberativa, sin embargo el fundamento de los derechos colectivos sigue débilmente desarrollado por Raz.

Finalmente la posibilidad de que sea el juez quien cree los derechos colectivos tiene implicancias en la teoría del derecho defendida por este autor.

El juez al resolver considerando «todos los factores en juego», debería tolerar una determinada práctica. No bastaría el ejercicio de una discrecionalidad fáctica. El derecho debería reconocerle una discrecionalidad que le permita acudir a consideraciones morales para resolver el asunto ${ }^{1}$. Ya he dicho que considero poco viable la posibilidad de un acuerdo como este, pero suponiendo que sea posible, 1) Raz no llamaría derecho a una resolución que acude a consideraciones morales; 2) se requerirían resoluciones reiteradas de diversos jueces para predicar que una práctica $\mathrm{Y}$ es tolerada por el sistema X $\mathrm{y}$, finalmente, esto demostraría que las sociedades multiculturales no actúan como unidades de agencia tal como lo entiende Joseph Raz.

\section{BIBLIOGRAFÍA}

Bardazano, G. (2007): «Liberalismos: Algunas consideraciones sobre el pluralismo de valores y los fines de la vida en Berlin y Raz», Revista Actio, N. ${ }^{\text {9 }}$. Recuperado el 15 de marzo de 2009.

En http://www.fhuce.edu.uy/public/actio/Textos/9/Bardazano9.pdf
Dworkin, R. (1992): «Liberal Comunity», en S. Avineri y A. de Shalit (Eds.). Comunitarianism and Individualism, pp. 205-223, New York, EE.UU.

Gargarella, R. (1999): «El embate comunitarista», en Las Teorías de la justicia después de Rawls (pp. 125-159), Barcelona, España: Ediciones Paidós Ibérica S.A.

Green, L. (2005): «Three Themes fron Raz», Oxford Journal of Legal Studies, 25, (3), pp. 503-525. Oxford, Reino Unido.

Griffin, J. (2004): «Group Rights», en L. Meyer, S. Paulson y T. Pogge (eds.). Rights, Culture, and the Law. Themes from the legal and political philosophi of Joseph Raz (pp. 161-182). Oxford, Reino Unido: Oxford University Press.

Raz, J. (1986): The Morality of Freedom, Oxford, Reino Unido: Oxford University Press.

- (1999): «Autonomía, tolerancia y el principio del daño», en R. Correa (Trad.). Revista de Estudios Públicos, (76), pp. 91-113. Santiago, Chile. (Trabajo original publicado en 1987).

- (2001): La Ética en el Ámbito Público. (M. L. Melón Trad.). Barcelona, España: Gedisa. (Trabajo original publicado en 1994).

Sentencia del 23 de noviembre de 2005, dictada por la primera sala del Tribunal Oral en lo Penal de Temuco, Chile. Dictada por los jueces Aner Padilla, Oscar Viñuela y Jorge Gonzáles, RIT 101-2005, RUC 0400415571-3.

Sentencia del 31 de mayo de 2006, dictada por la primera sala del Tribunal Oral en lo Penal de Temuco, Chile. Dictada por los jueces Oscar Viñuela, Ester Valencia y Héctor Hinojosa, RIT 049-2006, RUC 0500 $028957-6$.

Zambrano, J. y Agüero, C. (2009): «Multiculturalidad y discrecionalidad 
judicial en una sentencia penal: Análisis desde Joseph Raz», Revista de Derecho de la Pontificia Universidad Católica de Valparaíso, 32, (1), pp. 327-343. Valparaíso, Chile. Recuperado el 15 de marzo de 2009.

En http://www.scielo.cl/pdf/rdpucv/n32/ a09.pdf

\section{NOTAS}

* Agradezco los comentarios del grupo de investigación y estudios sobre Teoría del Derecho coordinado por el profesor Claudio Agüero San Juan de la Escuela de Derecho de la Universidad Católica de Temuco.
1 En otro trabajo he llamado a esta forma de discrecionalidad D1 para diferenciarla de las otras formas de discrecionalidad que desarrolla Raz (Zambrano y Agüero, 2009, p. 333). 